\title{
Mashare - Woody Vegetation
}

The vegetation at the Mashare study site shows a distinct difference between the tree communities of the Kavango River valley and those of the sand plain. Very little is left of the natural vegetation on the riverbank and the alluvial terrace on the Namibian site as most human activities in the area are centred along the Kavango River. The remaining woody vegetation is characterized by two tree communities: the Acacia nigrescens - Peltophorum africanum community, referred to as Kavango riverine vegetation, and the Acacia erubescens - A. luederitzii community, referred to as thornbush vegetation. Kavango riverine vegetation has a very dense tree layer with trees up to about $22 \mathrm{~m}$ high, much higher than the trees of the woodlands. The thornbush vegetation has a short tree layer and occurs in areas with high anthropogenic impact.

Woodlands further away from the river are mainly used for extensive grazing, hunting and harvesting of firewood, poles and fruits. Large areas burn annually because locals use fire to increase grazing and facilitate hunting. Commercial timber harvesting only started during the South African mandate period, in the 1950s, and focuses on Kiaat (Pterocarpus angolensis). Very few harvesting permits are currently being issued although there is some illegal logging taking place. Permanent settlement and agriculture is limited to the areas close to non-perennial riverbeds (omiramba or nomuramba - in Otjiherero, respectively, one of the Kavango languages) that have slightly better soils and where most of the boreholes are situated. The Acacia erioloba-Philenoptera nelsii community can be found near the banks of the omiramba. This riverbed vegetation is characterised by short trees, a dense grass and shrub layer with Croton gratissimus as another indicator tree species. It is the only community in the woodland area that appears to be influenced by soil composition, as all other tree communities occur on deep, nutrient poor Arenosols.

Differences between tree communities in the remaining woodland areas are small. The usage of the presence/absence of a species in circle 1 of the plots allows a distinction of the Baikiaea plurijuga Schinziophyton rautanenii community, Terminalia sericea community,

Table 1: Woody vegetation: plot design and key figures.

\begin{tabular}{|l|}
\hline Ecoregion \\
Zambezian Baikiaea woodlands \\
Sampling period \\
$2011-2013$ \\
Plots consist of three concentric circles \\
\hline 1) radius $10 \mathrm{~m}$ : trees with diameter at breast height $(\mathrm{dbh})>5 \mathrm{~cm}\left(314 \mathrm{~m}^{2}\right)$ \\
2) radius $20 \mathrm{~m}$ : trees with dbh $>20 \mathrm{~cm}\left(1,257 \mathrm{~m}^{2}\right)$ \\
3) radius $30 \mathrm{~m}$ : trees with dbh $>45 \mathrm{~cm}\left(2,827 \mathrm{~m}^{2}\right)$ \\
\hline Number of living trees measured \\
\hline 570 of which 389 in circle 1 \\
\hline Number of tree species in circle 1 \\
\hline $35 ; 28$ after removing species occurring only in one plot \\
Most common trees in circle 1 \\
\hline Terminalia sericea (58), Burkea africana (36), Baikiaea plurijuga (34) \\
Species with largest total basal area in circle 1 \\
\hline $\begin{array}{l}\text { Schinziophyton rautanenii }\left(30,057 \mathrm{~m}^{2}\right), \\
\text { Guibourtia coleosperma }\left(13,606 \mathrm{~m}^{2}\right), \\
\text { Pterocarpus angolensis }\left(9,052 \mathrm{~m}^{2}\right)\end{array}$ \\
\hline
\end{tabular}

Combretum psidioides community, Burkea africana community and Pterocarpus angolensis community. The main factors influencing the occurrence of these woodland communities appear to be the source and degree of disturbances, and to a lesser extent local differences in heights and aspects. The BaikiaeaSchinziophyton community has a denser tree layer with about $30 \%$ coverage and is

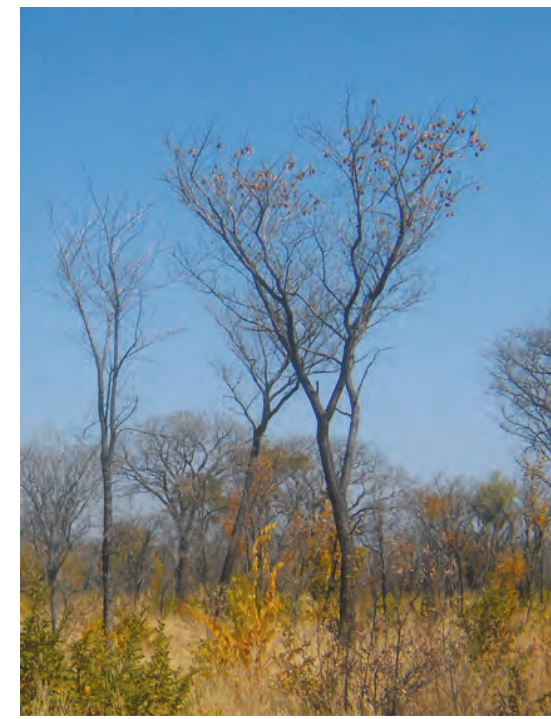

Fig. 1: Pterocarpus angolensis looses its leaves in the dry season (June 2011) (photo: V. De Cauwer). also characterized by the presence of Commiphora species. It often occurs on north facing slopes of dunes and is found further away from riverbeds $(>3 \mathrm{~km})$. The Terminalia sericea community is closer to the Kavango River $(<7 \mathrm{~km})$ and main road $(<4 \mathrm{~km})$ than the other communities and affected by cattle moving through on their way to the river. It is characterized by a dense shrub layer with pioneer Terminalia

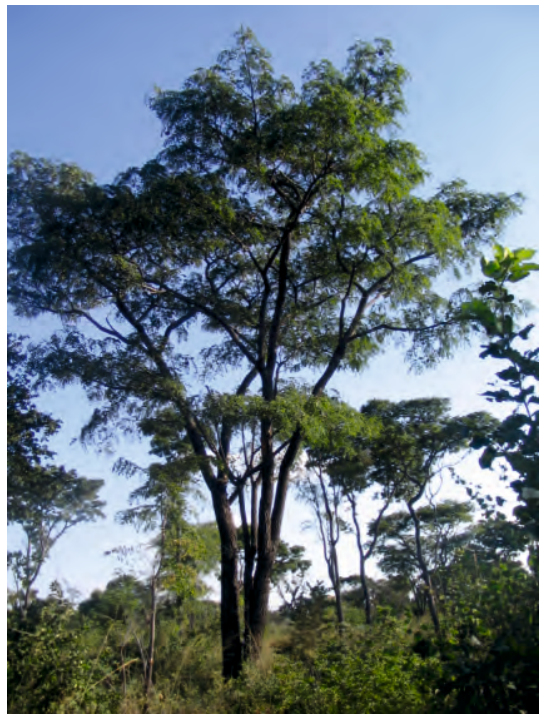

Fig. 2: Large Pterocarpus angolensis at the end of the rainy season (April 2011) (photo: V. De Cauwer). 


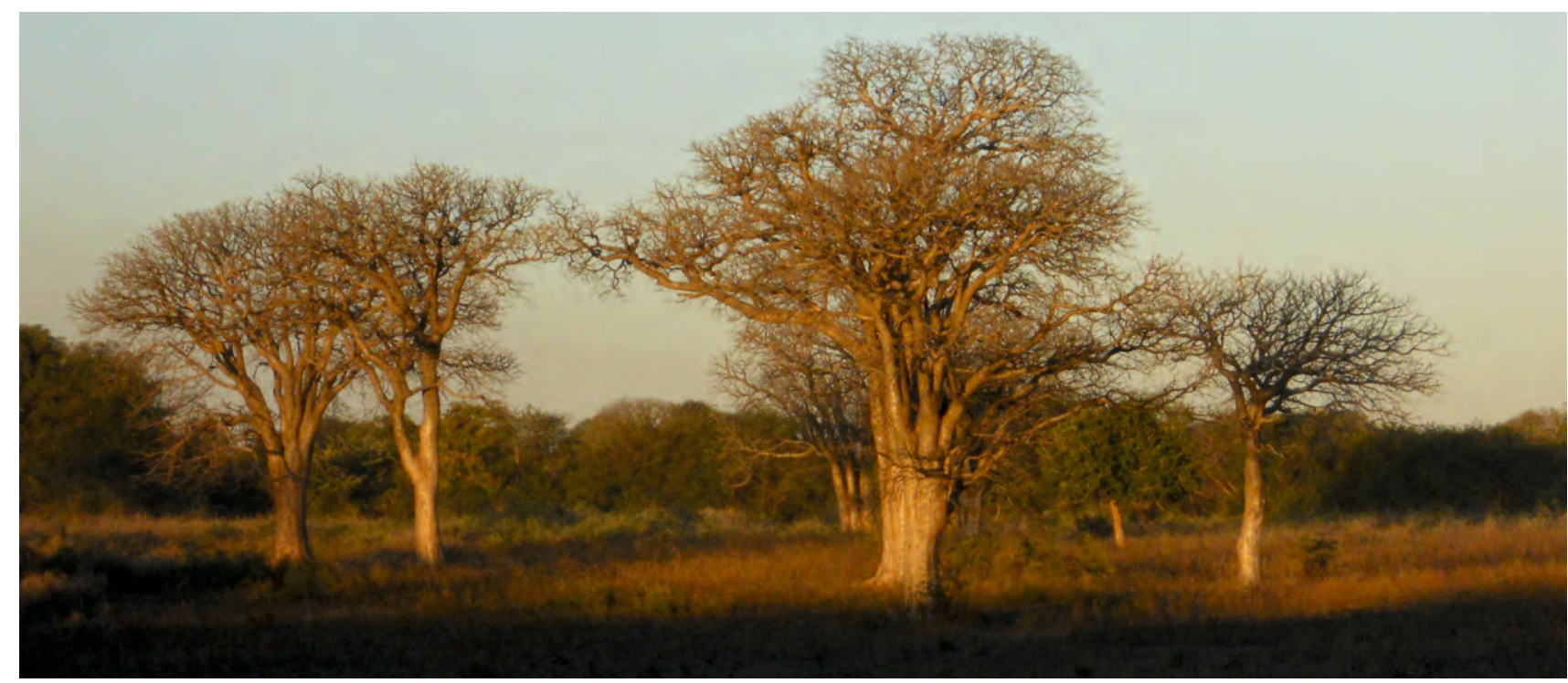

Fig. 3: Manketti (Schinziophyton rautanenii) on the alluvial terrace. The species is much less harvested than other tree species because of its fruits (June 2011) (photo: V. De Cauwer).

sericea as indicator species and only rarely contains Pterocarpus angolensis, hence can be referred to as secondary vegetation. The Combretum psidioides community has a very open tree layer (about $15 \%$ ), a denser grass layer and is closer situated to settlements and boreholes $(<5 \mathrm{~km})$ than the other woodland communities. The Burkea africana and the Pterocarpus angolensis community are very similar: both are found further away from the Kavango River, boreholes and settlements, often contain Pterocarpus angolensis and have a tree canopy coverage of about $20 \%$. Tree diameters are, however, smaller for the Burkea africana community and fire damage is more severe.

Table 2: Tree communities of the Mashare study site with indication of the most important species within circle $1(p<0.2)$ and an overview of tree inventory data. IV is the indicator value, with $100 \%$ representing a perfect indication, and $p$-values are calculated from a Monte Carlo permutation test. The values $\mathrm{DBH}_{\max }$ and $\mathrm{H}_{\max }$ reflect the average maximum diameter at breast height and the average maximum tree height per plot (all 3 circles).

\begin{tabular}{|c|c|c|c|c|c|}
\hline Tree communities & IV & $p$ & $\begin{array}{l}\text { Number } \\
\text { of plots }\end{array}$ & $\begin{array}{c}\mathrm{DBH}_{\max } \\
{[\mathrm{cm}]}\end{array}$ & $\begin{array}{l}\mathbf{H}_{\text {max }} \\
{[\mathrm{m}]}\end{array}$ \\
\hline Community 1: Acacia nigrescens - Peltophorum africanum & & & 2 & 66 & 20 \\
\hline Acacia nigrescens & 100 & 0.004 & & & \\
\hline Peltophorum africanum & 100 & 0.004 & & & \\
\hline Ziziphus mucronata & 33 & 0.199 & & & \\
\hline Community 2: Acacia erubescens - A. luederitzii & & & 4 & 35 & 9 \\
\hline Acacia erubescens & 75 & 0.005 & & & \\
\hline A. luederitzii & 50 & 0.021 & & & \\
\hline Community 3: Acacia erioloba - Philenoptera nelsii & & & 3 & 44 & 9 \\
\hline Acacia erioloba & 92 & 0.000 & & & \\
\hline Philenoptera nelsii & 67 & 0.006 & & & \\
\hline Croton gratissimus & 40 & 0.038 & & & \\
\hline Community 4: Baikiaea plurijuga - Schinziophyton rautanenii & & & 4 & 85 & 13 \\
\hline Commiphora spp. & 73 & 0.000 & & & \\
\hline Baikiaea plurijuga & 61 & 0.002 & & & \\
\hline Schinziophyton rautanenii & 54 & 0.036 & & & \\
\hline Community 5: Terminalia sericea & & & 5 & 56 & 12 \\
\hline Terminalia sericea & 32 & 0.000 & & & \\
\hline Community 6: Combretum psidioides & & & 12 & 49 & 11 \\
\hline Combretum psidioides & 62 & 0.000 & & & \\
\hline Community $7:$ Burkea africana & & & 8 & 50 & 13 \\
\hline Burkea africana & 71 & 0.000 & & & \\
\hline Community 8: Pterocarpus angolensis & & & 2 & 62 & 14 \\
\hline Pterocarpus angolensis & 48 & 0.016 & & & \\
\hline Dialium engleranum & 40 & 0.130 & & & \\
\hline
\end{tabular}




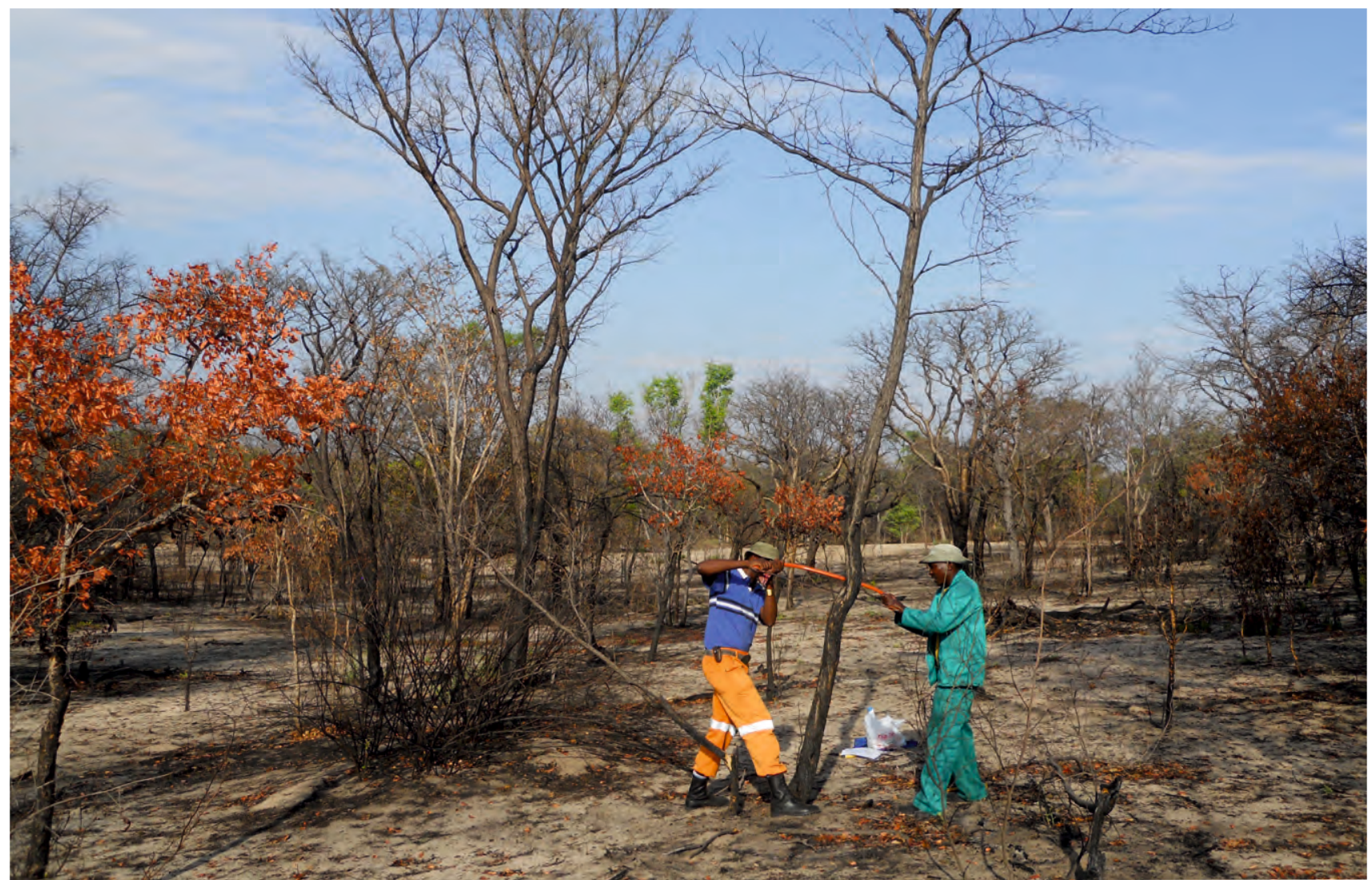

Fig. 4: Directorate of Forestry staff collecting research material in the state forest at Hamoye Forestry Research Station (October 2012) (photo: V. De Cauwer).

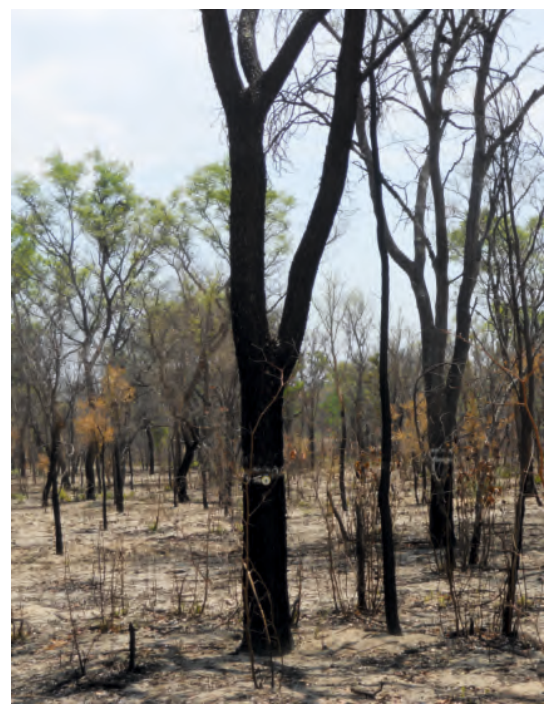

Fig. 5: Pterocarpus angolensis in a patch of woodland that was recently burned (October 2012) (photo: V. De Cauwer).

\section{Acknowledgments}

The data were collected in cooperation with colleagues of the Polytechnic of Namibia and the TFO project: Dr. Patrick Graz (Polytechnic of Namibia), Dr. Johannes Stoffels (University of Trier), Fransiska Kangombe (National Botanical

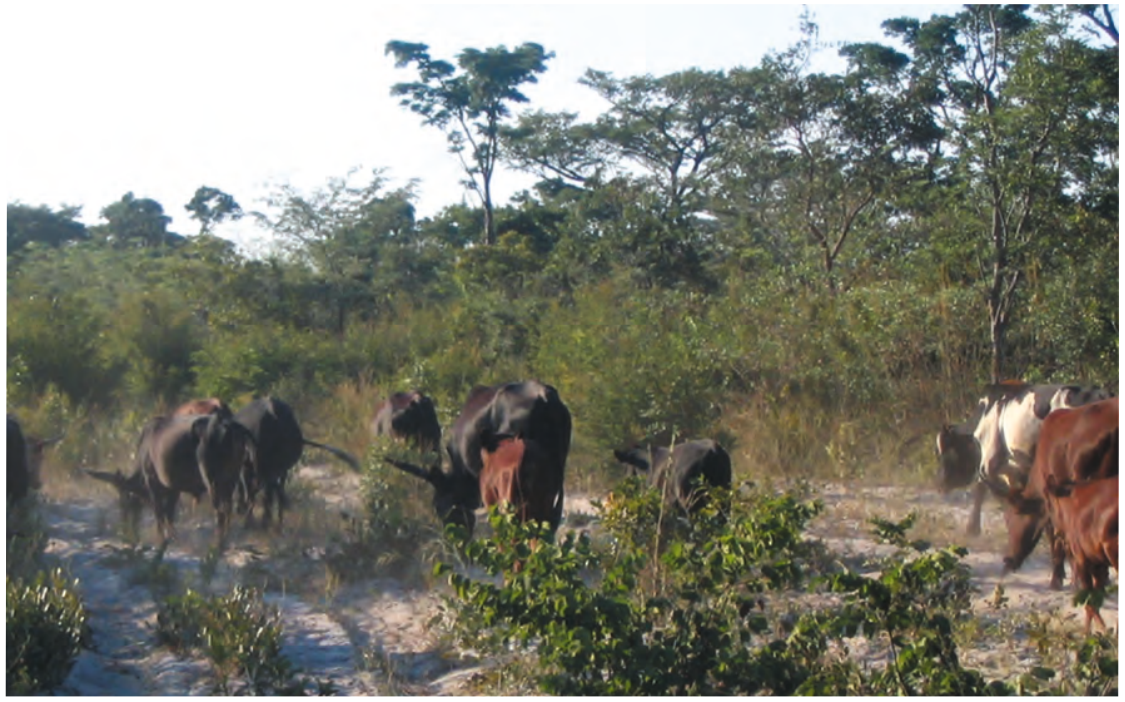

Fig. 6: Cattle being driven along a forest road (April 2011) (photo: V. De Cauwer).

Research Institute of Namibia), Rasmus Revermann (University of Hamburg), Jolien De Ruytter (University College Ghent), Selma Elago (Directorate of Forestry, Namibia) and Muwara Kamwanga (Polytechnic of Namibia). Data analysis was possible thanks to the guidance of Dr. Raf Aerts (University of Leuven). Thank you all.

This study was funded by the BMBF (The Future Okavango project). For details see authors' general acknowledgements in this volume. 
